\title{
Characterizing Subdiurnal Extreme Precipitation in the Midwestern United States
}

\author{
Nathan M. Hitchens, Robert J. Trapp, Michael E. Baldwin, And Alexander Gluhovsky \\ Department of Earth and Atmospheric Sciences, Purdue University, West Lafayette, Indiana
}

(Manuscript received 19 November 2008, in final form 30 July 2009)

\begin{abstract}
This research establishes a methodology to quantify the characteristics of convective cloud systems that produce subdiurnal extreme precipitation. Subdiurnal extreme precipitation events are identified by examining hourly precipitation data from 48 rain gauges in the midwestern United States during the period 19562005. Time series of precipitation accumulations for 6-h periods are fitted to the generalized Pareto distribution to determine the 10-yr return levels for the stations. An extreme precipitation event is one in which precipitation exceeds the 10-yr return level over a 6-h period. Return levels in the Midwest vary between 54 and $93 \mathrm{~mm}$ for 6-h events. Most of the precipitation contributing to these events falls within 1-2 h. Characteristics of the precipitating systems responsible for the extremes are derived from the National Centers for Environmental Prediction stage II and stage IV multisensor precipitation data. The precipitating systems are treated as objects that are identified using an automated procedure. Characteristics considered include object size and the precipitation mean, variance, and maximum within each object. For example, object sizes vary between 96 and $34480 \mathrm{~km}^{2}$, suggesting that a wide variety of convective precipitating systems can produce subdiurnal extreme precipitation.
\end{abstract}

\section{Introduction}

As with other convective weather hazards, inland flash flooding poses a significant forecasting and warning challenge that is made worse by its severe consequences on life, property, and agriculture. Reduction of this impact has come from advances in the understanding of the precipitation extremes that contribute to such flooding. Extreme rainfall is most often identified and studied in terms of 24-h rainfall accumulations (Bradley and Smith 1994; Konrad 2001; Schumacher and Johnson 2005, 2006; Silva and Berbery 2006; Smith et al. 1994), owing in part to a broader availability of data, especially from cooperative rain gauge networks (Hammer and Steurer 2003). For instance, Bradley and Smith (1994) used daily accumulation data from gauges to define extreme events and then further classified the events according to the strength of the larger-scale dynamical forcing.

Further advances have been made from studies relating extreme precipitation events to the type of precipitating weather systems responsible for the event. Recently, Schumacher and Johnson (2005) linked me-

Corresponding author address: Nathan M. Hitchens, Purdue University, 550 Stadium Mall Drive, West Lafayette, IN 47907-2051. E-mail: nhitchen@purdue.edu soscale convective systems (MCSs) and mesoscale convective complexes (MCCs) to daily extremes in the United States. Using hourly gauge data to examine the events more closely, and radar data for classification purposes, they found that about $65 \%$ of all the events were the result of MCSs, whereas $25 \%$ were driven by synopticscale processes. Other modes of cumulus convectionnamely, supercell thunderstorms - have also been shown to generate extreme amounts of rainfall (Bauer-Messmer et al. 1997; Smith et al. 2001). Bauer-Messmer et al. (1997) concluded that rainfall at time scales $<1 \mathrm{~h}$ are critical to flash-flood response.

Beyond operational forecasting and warning issues is the potential impact of anthropogenic global warming on precipitation extremes. Trends in observational data as well as climate model simulations have been used to project future increases in both the frequency and intensity of daily extremes (e.g., Chen et al. 2005; Emori and Brown 2005; Groisman et al. 2005; Hennessy et al. 1997; Karl and Knight 1998; Wilby and Wigley 2002). Whether or not these projections also apply to extremes at shorter time scales is an open question and, indeed, Trenberth $(1998,1999)$ and Trenberth et al. (2003) have recommended a closer examination of extreme precipitation at an hourly temporal scale in both observations and climate models. We follow this recommendation 
herein with our focus on subdiurnal extreme precipitation, as guided by the following, overarching questions: Do the convective cloud systems that produce extreme subdiurnal precipitation have unique characteristics, and are these events predictable?

Our motivation stems from the limited research to date on short time-scale rainfall extremes. Important contributions have been made by Winkler et al. (1988), who considered hourly rainfall in the conterminous United States by using the National Climatic Data Center's (NCDC) hourly precipitation dataset (HPD), gridded into cells with a horizontal dimension of $75 \mathrm{~km} \times 75 \mathrm{~km}$. Hourly precipitation was binned into four categories, the largest of which was for rainfall of $\geq 1.00$ in. $\mathrm{h}^{-1}\left(25.4 \mathrm{~mm} \mathrm{~h}^{-1}\right)$. Although regional variation existed, extreme hourly precipitation was found to occur later in the day, with this being more pronounced in the summer season. Similarly, Brooks and Stensrud (2000) examined the frequency of heavy rainfall using the HPD. They found a peak during June-August in hourly precipitation $\geq 1.00$ in. for much of the United States.

A concern expressed by Brooks and Stensrud (2000) is that the HPD is not adequate to resolve the spatial distribution of subdiurnal extreme precipitation events due to the coarse distribution of the gauge network (e.g., Bauer-Messmer et al. 1997; Smith et al. 1994). On the other hand, the national network of Weather Surveillance Radar-1988 Doppler (WSR-88D) radars provides derived rainfall products for a nearly continuous spatial domain, although these products are not without their own biases, for example (Fulton et al. 1998). A synthesis of these two precipitation datasets is available in a product produced by the National Centers for Environmental Prediction (NCEP) known as stage II and stage IV rainfall analysis (Fulton et al. 1998). These data are available hourly as a mosaic covering the conterminous United States in a $4 \mathrm{~km} \times 4 \mathrm{~km}$ grid. The present study makes use of the HPD as well as the stage II/IV data to identify and characterize precipitating systems that produce subdiurnal extreme precipitation.

This research is the first component of the multistage project mentioned earlier, with the ultimate goal of assessing the predictability of subdiurnal extremeprecipitation-producing systems. To meet this goal, a methodology to quantify the characteristics of these systems needs to be established. Accordingly, a sample set of subdiurnal extreme precipitation events are identified using the HPD and subsequently characterized from stage II or stage IV precipitation data.

A description of HPD analysis procedures, including our definition of an extreme, is presented in section 2 . In section 3, we couple the results of the HPD analysis



FIG. 1. Locations of the 48 rain gauges used to identify events.

to an analysis of stage II/IV data and characterize the precipitating systems associated with subdiurnal precipitation extremes. Two case studies are presented in section 4 to further illustrate such characteristics, and concluding remarks and future work are given in the last section.

\section{Rain gauge analysis}

Rain gauge stations that were continuously operating during the period 1956-2005 are considered for this study. We focus on the midwestern region of the United States, and 48 gauges are chosen to sample a broad area across this region (Fig. 1). The reason for the focus on the midwestern region is because of the lack of significant terrain in the area and the lack of tropical influences on the precipitation regime. This area is also well sampled by the stage II/IV precipitation product, and the region contains many agricultural areas that are affected by extreme precipitation events. These data required some initial preprocessing. First, data values are rounded to the nearest tenth of an inch, in response to an instrumentation change in most gauges in the 1960s that resulted in a subsequent decrease in recording precision from hundredths to tenths of inches. Second, erroneously large data values ( $>4$ in.) with no data in the hour preceding or following the large value are removed (see Brooks and Stensrud 2000).

Each 50-yr time series is fit to the generalized Pareto distribution (GPD), and exceedances over a high threshold are chosen by standard threshold selection techniques (e.g., Coles 2001). The GPD is used in favor of the generalized extreme value (GEV) distributions because 
TABLE 1. Locations and 10-yr return levels (mm) for 1-, 3-, 6-, and 12 -h periods at the 48 midwestern rain gauges.

\begin{tabular}{|c|c|c|c|c|}
\hline Gauge location & $1 \mathrm{~h}$ & $3 \mathrm{~h}$ & $6 \mathrm{~h}$ & $12 \mathrm{~h}$ \\
\hline \multicolumn{5}{|l|}{ ILLINOIS } \\
\hline Alexis & 48 & 62 & 72 & 84 \\
\hline Belleville & 57 & 72 & 83 & 95 \\
\hline Belvidere & 45 & 62 & 74 & 93 \\
\hline Cairo & 48 & 69 & 84 & 102 \\
\hline Chicago & 54 & 71 & 86 & 98 \\
\hline Springfield & 45 & 65 & 79 & 90 \\
\hline \multicolumn{5}{|l|}{ INDIANA } \\
\hline Brazil & 53 & 70 & 80 & 94 \\
\hline Columbia City & 41 & 56 & 65 & 71 \\
\hline Columbus & 46 & 58 & 71 & 81 \\
\hline Evansville & 44 & 62 & 72 & 83 \\
\hline Fort Wayne & 43 & 51 & 63 & 69 \\
\hline West Lafayette & 50 & 63 & 73 & 84 \\
\hline \multicolumn{5}{|l|}{ IOWA } \\
\hline Centerville & 53 & 68 & 78 & 86 \\
\hline Remsen & 48 & 64 & 75 & 82 \\
\hline Strawberry Point & 53 & 67 & 72 & 82 \\
\hline Wallin & 52 & 76 & 93 & 100 \\
\hline Washington & 48 & 60 & 68 & 75 \\
\hline Webster City & 52 & 65 & 74 & 84 \\
\hline \multicolumn{5}{|l|}{ MICHIGAN } \\
\hline Ann Arbor & 42 & 52 & 54 & 61 \\
\hline Muskegon & 34 & 46 & 56 & 67 \\
\hline Owosso & 42 & 50 & 56 & 64 \\
\hline Trout Lake & 48 & 53 & 59 & 69 \\
\hline Vanderbilt & 34 & 44 & 54 & 62 \\
\hline Wakefield & 46 & 54 & 64 & 76 \\
\hline \multicolumn{5}{|l|}{ MINNESOTA } \\
\hline Gulf Lake & 50 & 64 & 68 & 75 \\
\hline Le Sueur & 50 & 64 & 73 & 80 \\
\hline Luverne & 50 & 57 & 64 & 72 \\
\hline Rushford & 55 & 69 & 74 & 80 \\
\hline Thief Lake & 41 & 53 & 61 & 72 \\
\hline Wales & 36 & 46 & 61 & 62 \\
\hline \multicolumn{5}{|l|}{ MISSOURI } \\
\hline Clearwater & 50 & 62 & 75 & 90 \\
\hline Downing & 50 & 58 & 71 & 81 \\
\hline Jefferson City & 46 & 57 & 61 & 72 \\
\hline Miller & 55 & 70 & 84 & 103 \\
\hline Steffenville & 46 & 60 & 71 & 83 \\
\hline Warrensburg & 54 & 75 & 94 & 109 \\
\hline \multicolumn{5}{|l|}{ OHIO } \\
\hline Cambridge & 51 & 55 & 61 & 70 \\
\hline Germantown & 47 & 55 & 61 & 73 \\
\hline Mansfield & 41 & 53 & 61 & 71 \\
\hline Portsmouth & 46 & 57 & 67 & 74 \\
\hline Toledo & 39 & 51 & 61 & 69 \\
\hline Youngstown & 39 & 53 & 60 & 71 \\
\hline
\end{tabular}

TABLE 1. (Continued)

\begin{tabular}{lcccc}
\hline \hline Gauge location & $1 \mathrm{~h}$ & $3 \mathrm{~h}$ & $6 \mathrm{~h}$ & $12 \mathrm{~h}$ \\
\hline WISCONSIN & & & & \\
Babcock & 44 & 61 & 68 & 78 \\
Blanchardville & 51 & 67 & 72 & 80 \\
Green Bay & 39 & 48 & 55 & 63 \\
Hartford & 49 & 59 & 65 & 75 \\
New Richmond & 47 & 58 & 70 & 75 \\
Park Falls & 50 & 57 & 60 & 68 \\
\hline
\end{tabular}

the GEV uses a block maxima approach to fit the observations instead of the peak-over-threshold approach used by the GPD. The block maxima approach limits the number of observations used, whereas the peak-overthreshold approach is preferred in this study because it uses any observation that exceeds the threshold. To investigate precipitation at other subdiurnal time frames, the observations in an HPD time series are grouped into consecutive 3-h periods [0000-0300 local standard time (LST), 0400-0600 LST, and so on], 6-h periods (00000600 LST, 0700-1200 LST, and so on), and 12-h periods (0000-1200 LST, and so on), and 10-yr return levels are calculated for each of these groupings of observations (Table 1). A moving-window approach was considered to construct the observation periods but was dismissed. However, the issue of underestimation based on window selection as well as other aspects of defining extreme events from the HPD will be more carefully explored in future work, based on reliable estimates of the tail index (e.g., Qi 2008), a key parameter in predicting extreme events. Using these return levels, an extreme precipitation event is defined as a 6-h period that surpasses the respective 10-yr return level at a gauge. The choice of a 6$\mathrm{h}$ period follows the upper-temporal boundary for events that commonly produce flash flooding (NOAA 2006).

Over the 48 gauges, the return levels for 6-h events range from 54 to $94 \mathrm{~mm}$. In general, the return levels are lower in the states that are farther north (Michigan, Minnesota, Wisconsin) as well as in Ohio, which is the easternmost state. During the 50-yr period of study, there are a total of 336 events that surpass the return level for 6-h events. Furthermore, $78 \%$ of the 6-h extreme events contain a period that also qualifies as a $3-\mathrm{h}$ event, and $71.8 \%$ of the events that meet the criteria for both 3- and 6-h events are part of a 12-h event.

If each 6-h extreme event is analyzed by hour (the highest one hour of precipitation, the highest two consecutive hours of precipitation, and so on), as in Fig. 2, it is seen that on average the hour with the highest precipitation accounts for nearly half of the total rainfall. Likewise, the 2-h period of highest precipitation accounts for $71 \%$ of the total accumulated rainfall during the 6 -h event. 


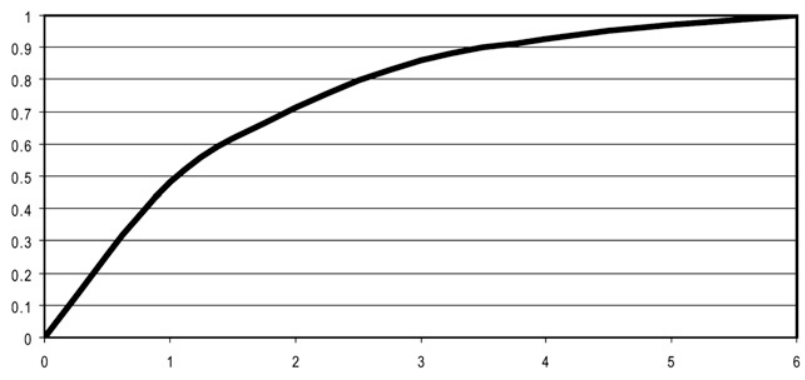

FIG. 2. Contribution to the 6-h total by largest precipitation accumulation over consecutive hours as a mean of all 36 events.

\section{Stage II/IV precipitation analysis}

In this section, we consider only those extreme precipitation events that additionally have corresponding stage II/IV precipitation data, which are available beginning May 1996 (January 2002 for stage IV). Of the 336 total gauge events, 36 meet this additional criterion. As indicated in Table 2, each event occurs on a different date, hence they are treated here as independent samples.

The stage II/IV data are analyzed at the hour of peak precipitation at the gauge, as well as for several hours preceding and following the peak hour, using the Baldwin object identification algorithm (BOIA; Baldwin et al. 2005). This algorithm forms precipitation "objects" from pixels with values over a user-defined threshold (Figs. 3a,b). For the purpose of this study, the threshold is $6 \mathrm{~mm} \mathrm{hr}^{-1}$, which is considered the lower bounds for convective rainfall (Johnson and Hamilton 1988). Objects are constrained by a user-defined search radius, defined here as one pixel, which has physical dimensions of $4 \mathrm{~km} \times 4 \mathrm{~km}$. Hence, areas of pixels with no more than a single-pixel gap are grouped into objects (Figs. $3 \mathrm{~b}, \mathrm{c})$. A 1-pixel search radius is used with the BOIA to identify objects to study only the area of intense rainfall that was directly affecting the gauge. A larger search radius may include areas of precipitation in the object that are being influenced by different processes. The BOIA then diagnoses attributes of these objects, such as size (area); precipitation mean, maximum, and variance; and centroid location.

The characteristics of precipitating systems associated with the gauge extremes are revealed by the attributes of the objects affecting the gauge location at the time of peak event precipitation (Table 2). For example, the size of these objects varies between 34480 and $96 \mathrm{~km}^{2}$, with a mean of $8054 \mathrm{~km}^{2}$. As a point of reference, an MCC has an interior cloud shield (satellite IR brightness temperature $\leq-52^{\circ} \mathrm{C}$ ) with an area $\geq 50000 \mathrm{~km}^{2}$, which corresponds to its convective region (Maddox 1980). Hence, morphologically, the associated precipitating sys- tems range from MCCs and large MCSs to much smaller, relatively isolated, and slow-moving convective storms (see section 4). These smaller systems, and thus smaller objects, may pose challenges for predictability, whereas larger systems present a potential for more widespread flooding.

The size of the object and hence precipitating system would appear to relate to the object's precipitation characteristics. In comparing the size of an object at the time of peak precipitation at the gauge to the maximum object precipitation (Fig. 4), there is a moderately positive trend in the data $\left(R^{2}\right.$ value of 0.3$)$, suggesting that larger objects have a higher amount of maximum precipitation. Object size also correlates positively to precipitation variance, because maximum precipitation relates nearly linearly to variance (Table 2). It should be noted that discrepancies between the gauge maximum precipitation and the corresponding object's maximum precipitation value are partly because of spatial offsets between the gauge location and the location of the object maximum and also because of quality control procedures performed during the processing of stage II and stage IV data, effectively dampening these object maxima.

\section{Case studies}

In this section, we highlight two of the events in our database that illustrate the range of association between a gauge extreme and its corresponding precipitation object.

\section{a. Wallin, Iowa: 7 August 1999}

On 7 August 1999 and beginning at 0500 UTC, $157 \mathrm{~mm}$ of rain were recorded over six hours at the gauge located in Wallin, Iowa. This total surpassed the return level for 6-h events $(93 \mathrm{~mm})$, and the maximum 3-h accumulation of $119 \mathrm{~mm}$ also exceeded the 3-h event return level of $76 \mathrm{~mm}$ for this location. The hour ending 0800 UTC was the hour of peak precipitation, with $46 \mathrm{~mm}$ of rainfall. This hour accounted for $29 \%$ of the 6-h event total, and with the addition of the precipitation from the next consecutive hour, $38 \mathrm{~mm}$, these two hours make up more than $52 \%$ of the total.

The stage II data for the peak hour of precipitation are shown in Fig. 5a, the radar reflectivity factor at 0700 UTC from the Des Moines, Iowa, WSR-88D (DMX) is shown in Fig. 5b, and the results of the BOIA applied to the stage II data are given in Fig. 5c. There are two precipitation maxima in Iowa during this hour, with the greater of the two near Wallin. The object affecting the gauge location, object number 48 , has a size of $7616 \mathrm{~km}^{2}$, a mean precipitation of $14 \mathrm{~mm}$, and a maximum precipitation of $58 \mathrm{~mm}$. 
TABLE 2. Attributes of precipitation objects associated with extreme precipitation.

\begin{tabular}{|c|c|c|c|c|c|c|}
\hline Location & Date & Gauge precipitation (mm) & Size $\left(\mathrm{km}^{2}\right)$ & Mean $(\mathrm{mm})$ & Variance & $\overline{\operatorname{Max}(\mathrm{mm})}$ \\
\hline Alexis & 4 Aug 19982000 & 51 & 1840 & 9 & 5.53 & 16 \\
\hline Cairo & 26 Jul 20011400 & 46 & 5856 & 11 & 20.14 & 25 \\
\hline Chicago & 17 Jul 19962000 & 36 & 5472 & 11 & 14.42 & 23 \\
\hline Chicago & 8 Aug 20011400 & 38 & 3888 & 14 & 46.13 & 30 \\
\hline Brazil & 8 Sep 19970000 & 76 & 768 & 11 & 18.03 & 26 \\
\hline Columbia City & 28 June 20051000 & 36 & 288 & 14 & 48.00 & 30 \\
\hline Columbus & 16 Apr 19980200 & 38 & 13248 & 10 & 15.44 & 26 \\
\hline Columbus & 10 Jul 20030400 & 25 & 14144 & 17 & 100.31 & 63 \\
\hline Evansville & 9 Jul 20010900 & 23 & 4584 & 10 & 11.56 & 22 \\
\hline Fort Wayne & 7 Jul 20030300 & 46 & 10496 & 13 & 31.41 & 34 \\
\hline West Lafayette & 12 Jun 20041000 & 48 & 17952 & 14 & 61.37 & 60 \\
\hline Centerville & 30 May 20040800 & 46 & 5488 & 12 & 28.01 & 31 \\
\hline Remsen & 5 Aug 20020600 & 41 & 6704 & 14 & 37.76 & 46 \\
\hline Remsen & 15 Sep 20040400 & 46 & 16016 & 16 & 72.10 & 50 \\
\hline Remsen & 25 Jun 20051300 & 41 & 2096 & 12 & 12.63 & 22 \\
\hline Strawberry Point & 18 Aug 20051300 & 28 & 10416 & 14 & 54.84 & 47 \\
\hline Wallin & 7 Aug 19990800 & 46 & 7616 & 14 & 100.73 & 58 \\
\hline Ann Arbor & 16 Jul 20051400 & 56 & 96 & 18 & 48.07 & 31 \\
\hline Owosso & 22 Sep 20052100 & 38 & 4512 & 11 & 12.79 & 22 \\
\hline Wakefield & 25 Aug 20042300 & 48 & 1120 & 14 & 20.94 & 22 \\
\hline Gull Lake & 8 Jul 20020500 & 41 & 12432 & 14 & 57.87 & 55 \\
\hline Thief Lake & 31 Jul 20012300 & 20 & 10768 & 14 & 21.78 & 27 \\
\hline Wales & 5 Jul 19990700 & 23 & 13424 & 12 & 26.44 & 33 \\
\hline Downing & 2 Aug 20041400 & 33 & 8624 & 12 & 27.55 & 32 \\
\hline Miller & 26 Sep 19960800 & 53 & 17504 & 12 & 26.58 & 33 \\
\hline Miller & 5 Oct 19980800 & 38 & 4496 & 9 & 4.72 & 15 \\
\hline Cambridge & 12 Aug 20011500 & 61 & 2176 & 14 & 25.63 & 30 \\
\hline Germantown & 27 Jul 20021200 & 48 & 7360 & 17 & 76.99 & 41 \\
\hline Portsmouth & 24 Aug 19991800 & 36 & 416 & 9 & 4.76 & 14 \\
\hline Toledo & 20 Sep 19970400 & 46 & 6016 & 15 & 42.59 & 30 \\
\hline Youngstown & 22 Jul 20030100 & 36 & 7552 & 18 & 92.16 & 51 \\
\hline Babcock & 25 Jun 19980500 & 36 & 6000 & 11 & 13.17 & 26 \\
\hline Babcock & 19 Jul 19990600 & 38 & 416 & 7 & 0.58 & 9 \\
\hline New Richmond & 19 Jun 20021200 & 41 & 4720 & 10 & 15.75 & 31 \\
\hline New Richmond & 5 Oct 20050400 & 41 & 34480 & 10 & 14.34 & 40 \\
\hline Park Falls & 8 Jul 20021100 & 28 & 20976 & 11 & 32.09 & 42 \\
\hline Mean & & 40.78 & 8054 & 12.68 & 34.53 & 33.09 \\
\hline Standard dev & & 11.11 & 7156 & 2.68 & 27.19 & 13.44 \\
\hline Minimum & & 20.32 & 96 & 6.78 & 0.58 & 9.19 \\
\hline Maximum & & 76.20 & 34480 & 18.00 & 100.73 & 62.75 \\
\hline
\end{tabular}

The Wallin, Iowa, object is chosen as an example of an average-sized object, with its mean size closest to the mean size of all 36 events $\left(8054 \mathrm{~km}^{2}\right)$. However, the mean and maximum precipitation in this object is greater than the averages of all events. In terms of a representative radar reflectivity presentation (Fig. 5b), this precipitating system most closely matches the "training line/adjoining stratiform" classification employed by Schumacher and Johnson (2005).

\section{b. Columbia City, Indiana: 28 June 2005}

On 28 June 2005, a total of $81 \mathrm{~mm}$ of rain was measured at the gauge located in Columbia City, Indiana, over a 6-h period beginning with the hour ending at 0900 UTC. This surpassed the 10-yr return level of $65 \mathrm{~mm}$. A 3-h accu- mulation of $76 \mathrm{~mm}$ also exceeded the 10-yr return level of $56 \mathrm{~mm}$. The $36 \mathrm{~mm}$ of rain that fell during the hour of peak precipitation (hour ending at 1000 UTC) accounted for $44 \%$ of the 6-h accumulation. An additional $28 \mathrm{~mm}$ was recorded the next hour, with the 2 -h precipitation making up $78 \%$ of the total.

A plot of the stage IV data for the hour of peak precipitation is provided in Fig. 6a, the radar reflectivity factor at 0902 UTC from the northern Indiana WSR88D (IWX) is shown in Fig. 6b, and the associated objects identified by the BOIA is presented in Fig. 6c. It is seen that the area of precipitation affecting the gauge at Columbia City is relatively small, but a concentrated area of heavier precipitation can be observed. The object (\#207) can be characterized as having a size of 


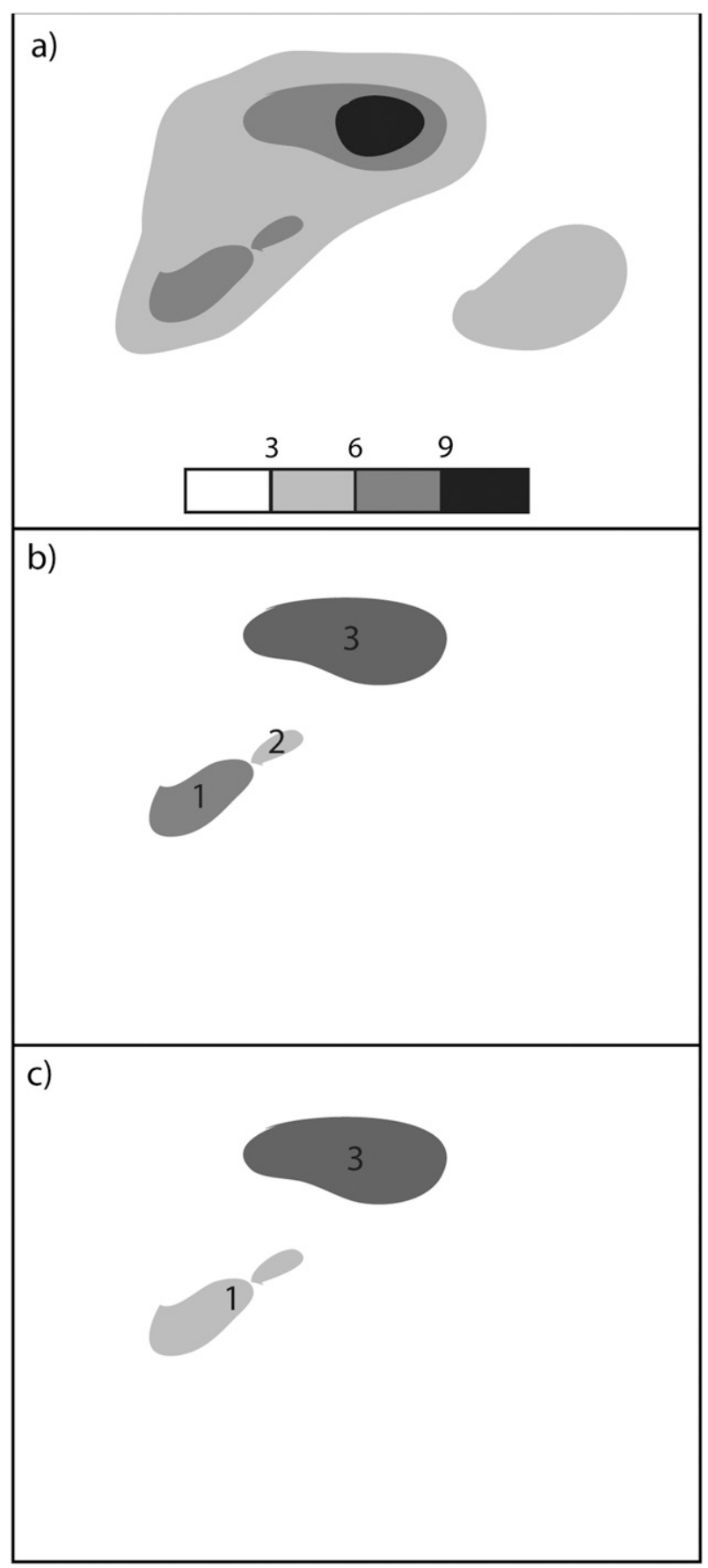

FIG. 3. Illustration of the BOIA. (a) An idealization of stage II/IV precipitation is shown. (b) The objects are identified after the $6 \mathrm{~mm}$ threshold is applied to (a). Objects 1 and 2 are separated by 1 pixel and are individually labeled at this point in the algorithm. (c) The last object labels are established after applying the "search radius" of 1 pixel.

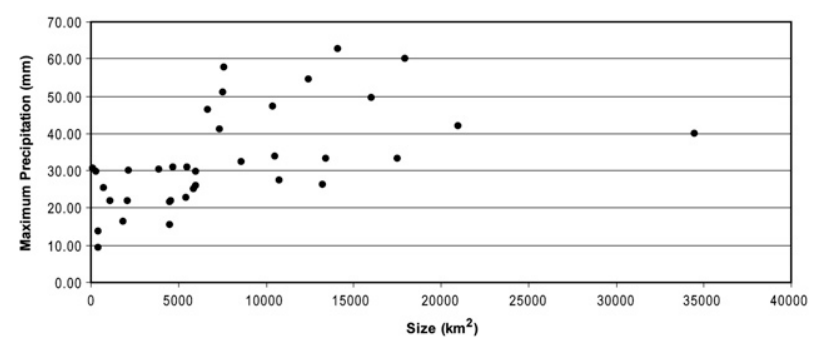

FIG. 4. Scatterplot comparing object size to maximum precipitation for the 36 events.

$288 \mathrm{~km}^{2}$, a mean precipitation of $14 \mathrm{~mm}$, and a precipitation maximum within the object of $30 \mathrm{~mm}$.

The Columbia City, Indiana, event is chosen as an example of an extreme-precipitation-producing system that is much smaller in size than most other events. The mean precipitation, however, is above average over all events. The maximum precipitation in this case compares well to the accumulation recorded by the gauge, suggesting a fortuitous track of the precipitation core over the rain gauge station. We would classify this precipitating system as a relatively isolated convective storm and also relatively slow moving, because the average propagation speed of the object is $3.61 \mathrm{~m} \mathrm{~s}^{-1}$. In comparison, the object of interest in section $4 \mathrm{~b}$ had an average propagation speed of $7.50 \mathrm{~m} \mathrm{~s}^{-1}$.

\section{Conclusions}

The goal of this work was to establish a methodology to identify and characterize extreme subdiurnal precipitation events, which ultimately will be used toward the assessment of the predictability of subdiurnal extremeprecipitation-producing systems. Such systems are capable of generating inland flash floods, which pose a significant hazard to life, property, and agriculture. HPD data were examined to define thresholds for extreme events at selected locations. An extreme precipitation event is one in which precipitation exceeded the 10 -yr return level over a 6 -h period. Our analysis revealed that the majority of precipitation in these subdiurnal extremes fell over one or two hours. We suggest here the possibility that many of the extreme events defined by daily accumulations are also influenced heavily by precipitation over a few hours.

Those events that had corresponding stage II/IV data were examined further using the BOIA, with object attributes compiled at the hour of peak gauge precipitation. The use of the BOIA is a unique approach for the quantitative and objective characterization of precipitating systems, and it showed that the size (area) and maximum precipitation of the systems varied strongly across the 



FIG. 5. Plots of the (a) stage II precipitation, (b) radar reflectivity, and (c) the objects identified by the BOIA for the event at Wallin, Iowa, on 7 Aug 1999 for the hour ending at 0800 UTC. The gauge location is identified in (a).

events. In particular, some events featured relatively small, isolated, convective storms that likely would not have been considered in other classification schemes. The analyses of the sample events for which stage II/IV precipitation data are available provide basic character-

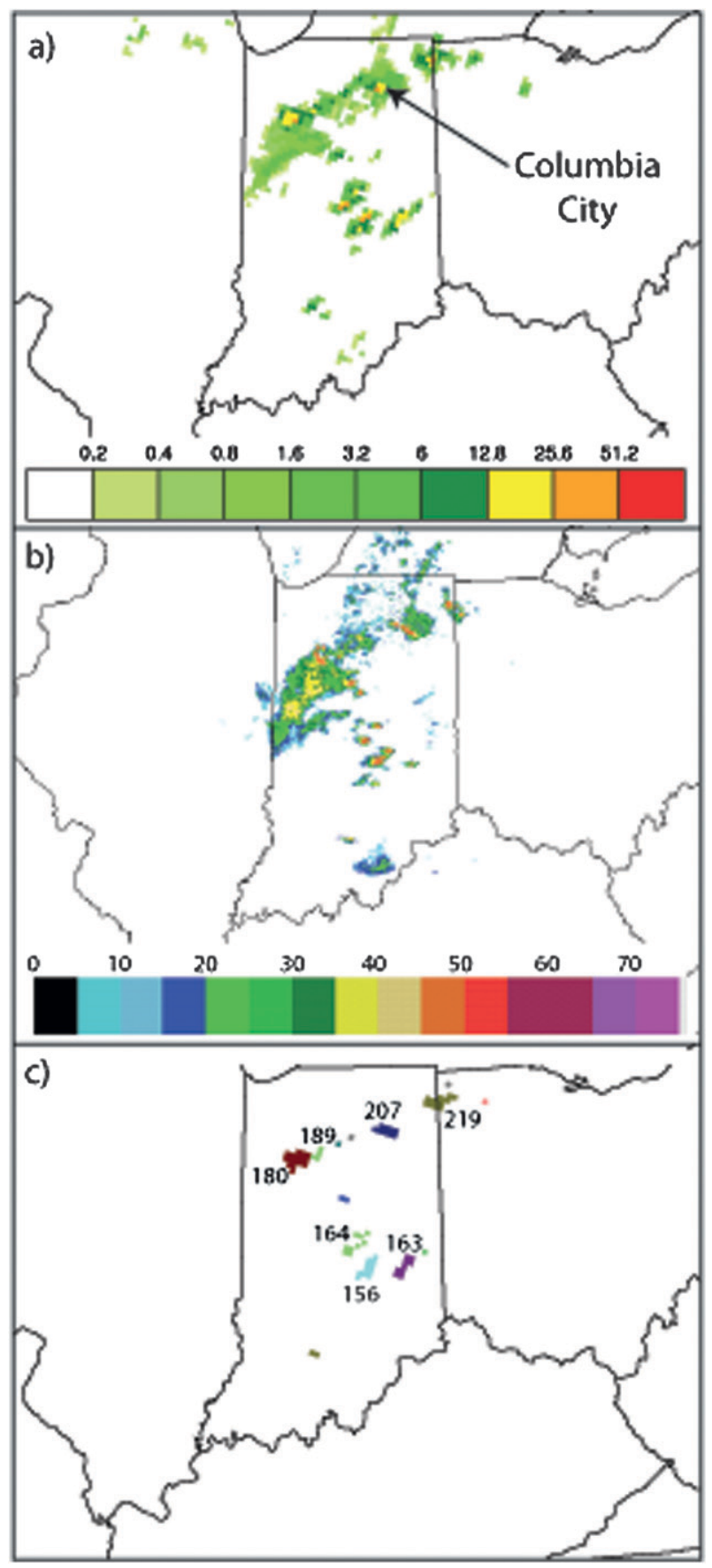

FIG. 6. Same as Fig. 5 but for Columbia City, Indiana, on 28 Jun 2005 for the hour ending at 1000 UTC.

istics for these events-information which is currently unknown.

This study has built on the work of Brooks and Stensrud (2000), Schumacher and Johnson (2006), Smith et al. (2001), Winkler et al. (1988), and others, and serves as an important next step in characterizing subdiurnal extreme precipitation events. It is important to emphasize 
that the current study did not attempt to identify extreme precipitating systems per se but rather sought to characterize those systems that produced extreme precipitation at specific point locations. Hence, one branch of our future research will be devoted to the identification of extreme systems, through the use of the BOIA. We will also attempt to relate these events to the largerscale forcing, and to explore their predictability, by way of high-resolution model simulations.

Acknowledgments. Analysis of the HPD time series was enabled by the Extremes Toolkit (extRemes), developed by the University Corporation for Atmospheric Research and the R Project for Statistical Computing. The constructive comments and suggestions made by the anonymous reviewers helped improve the manuscript. The National Science Foundation is acknowledged for its support of this research through Grants ATM-0541491 and ATM-0756624.

\section{REFERENCES}

Baldwin, M. E., J. S. Kain, and S. Lakshmivarahan, 2005: Development of an automated classification procedure for rainfall systems. Mon. Wea. Rev., 133, 844-862.

Bauer-Messmer, B., J. A. Smith, M. L. Baeck, and W. J. Zhao, 1997: Heavy rainfall: Contrasting two concurrent Great Plains thunderstorms. Wea. Forecasting, 12, 785-798.

Bradley, A. A., and J. A. Smith, 1994: The hydrometeorological environment of extreme rainstorms in the southern Great Plains of the United States. J. Appl. Meteor., 33, 1418-1431.

Brooks, H. E., and D. J. Stensrud, 2000: Climatology of heavy rain events in the United States from hourly precipitation observations. Mon. Wea. Rev., 128, 1194-1201.

Chen, M., H. Mao, R. Talbot, and D. Pollard, 2005: Changes in precipitation characteristics over North America for doubled $\mathrm{CO}_{2}$. Geophys. Res. Lett., 32, L19716, doi:10.1029/ 2005 GL024535.

Coles, S., 2001: An Introduction to Statistical Modeling of Extreme Values. Springer Verlag, 208 pp.

Emori, S., and S. J. Brown, 2005: Dynamic and thermodynamic changes in mean and extreme precipitation under changed climate. Geophys. Res. Lett., 32, L17706, doi:10.1029/ 2005GL023272.

Fulton, R. A., J. P. Breidenbach, D. J. Seo, D. A. Miller, and T. O'Bannon, 1998: The WSR-88D rainfall algorithm. Wea. Forecasting, 13, 377-395.

Groisman, P. Y., R. W. Knight, D. R. Easterling, T. R. Karl, G. C. Hegerl, and V. A. N. Razuvaev, 2005: Trends in in- tense precipitation in the climate record. J. Climate, $\mathbf{1 8}$ 1326-1350.

Hammer, G., and P. Steurer, 2003: Data documentation for data set 3240 (DSI-3240) hourly precipitation data. National Climatic Data Center Rep., 10 pp.

Hennessy, K. J., J. M. Gregory, and J. F. B. Mitchell, 1997: Changes in daily precipitation under enhanced greenhouse conditions. Climate Dyn., 13, 667-680.

Johnson, R. H., and P. J. Hamilton, 1988: The relationship of surface pressure features to the precipitation and air-flow structure of an intense midlatitude squall line. Mon. Wea. Rev., 116, 1444-1472.

Karl, T. R., and R. W. Knight, 1998: Secular trends of precipitation amount, frequency, and intensity in the United States. Bull. Amer. Meteor. Soc., 79, 231-241.

Konrad, C. E., 2001: The most extreme precipitation events over the eastern United States from 1950 to 1996: Considerations of scale. J. Hydrometeor., 2, 309-325.

Maddox, R. A., 1980: Mesoscale convective complexes. Bull. Amer. Meteor. Soc., 61, 1374-1387.

NOAA, cited 2006: Definitions of flood and flash flood. [Available online at http://www.srh.noaa.gov/mrx/hydro/flooddef.php.]

Qi, Y., 2008: Bootstrap and empirical likelihood methods in extremes. Extremes, 11, 81-97.

Schumacher, R. S., and R. H. Johnson, 2005: Organization and environmental properties of extreme-rain-producing mesoscale convective systems. Mon. Wea. Rev., 133, 961-976.

— , and - 2006: Characteristics of U.S. extreme rain events during 1999-2003. Wea. Forecasting, 21, 69-85.

Silva, V. B. S., and E. H. Berbery, 2006: Intense rainfall events affecting the La Plata Basin. J. Hydrometeor., 7, 769-787.

Smith, J. A., A. A. Bradley, and M. L. Baeck, 1994: The space-time structure of extreme storm rainfall in the southern plains. $J$. Appl. Meteor., 33, 1402-1417.

— M. L. Baeck, Y. Zhang, and C. A. Doswell, 2001: Extreme rainfall and flooding from supercell thunderstorms. J. Hy drometeor., 2, 469-489.

Trenberth, K. E., 1998: Atmospheric moisture residence times and cycling: Implications for rainfall rates and climate change. Climatic Change, 39, 667-694.

_ 1999: Conceptual framework for changes of extremes of the hydrological cycle with climate change. Climatic Change, $\mathbf{4 2}$, 327-339.

— A. G. Dai, R. M. Rasmussen, and D. B. Parsons, 2003: The changing character of precipitation. Bull. Amer. Meteor. Soc., 84, 1205-1217.

Wilby, R. L., and T. M. L. Wigley, 2002: Future changes in the distribution of daily precipitation totals across North America. Geophys. Res. Lett., 29, 1135, doi:10.1029/2001GL013048.

Winkler, J. A., B. R. Skeeter, and P. D. Yamamoto, 1988: Seasonal variations in the diurnal characteristics of heavy hourly precipitation across the United States. Mon. Wea. Rev., 116, 16411658. 